\title{
Editorial
}

\section{Central Nervous System Tuberculosis - The Gray Area in Tuberculosis Treatment}

As per the global tuberculosis (TB) report of 2017, the estimated incidence of TB in India was approximately $2,800,000$ accounting for about a quarter of the world's TB cases, 15,000 being multidrug-resistant TB with mortality of 42,000 patients. $^{[1]}$ The incidence and prevalence of central nervous system-TB (CNS-TB) are unknown but roughly accounts for $1 \%-10 \%$ of all $\mathrm{TB}$ cases.

The spectrum of CNS-TB is wide. In the brain, it can present as tuberculous meningitis (TBM), tubercular abscess, tuberculoma, or hypertrophic pachymeningitis. In the spinal cord, tuberculous myelitis, spinal tuberculoma, Pott's spine with epidural abscess, and arachnoiditis are the common manifestations. It is widely accepted that TB bacilli reach the CNS through hematogenous spread. Foci of granuloma (Rich foci) develop around the bacilli to contain the infection, rupture of these foci into subarachnoid space causes intense inflammatory reaction causing TBM. ${ }^{[2]}$ Tumor necrosis factor-alpha (TNF- $\alpha$ ) and interferon-gamma (IFN- $\gamma$ ) are important mediators in these events. The clinical manifestations of TBM are chiefly due to this inflammation, and hence, dexamethasone is useful as an adjuvant in TBM but not in tuberculoma. ${ }^{[3]}$

Why a patient develops TBM, TB abscess or tuberculoma is vaguely understood, but as of the current understanding of the pathogenesis of $\mathrm{TB}$, is believed to be related to host immunity. T-helper cells of Th1 type are important in the immune response against TB bacilli. These cells secrete IFN- $\gamma$ and interleukin-2. IFN- $\gamma$ stimulates macrophages and transforms them into giant cells and forms a reactive granuloma around TB bacilli. In conditions compromising cellular immunity including, but not limited to human immunodeficiency virus infection, glucocorticoid use, diabetes mellitus, malnutrition, and treatment with TNF- $\alpha$ inhibitors, this immune response is inadequate to contain the bacilli and results in a clinical disease in the extreme end of the spectrum, i.e. TBM. Those with impaired cellular immunity but with a better immune status than the former group develops tuberculoma.

In the present issue of the Journal, the authors studied 72 patients with CNS-TB who were treated with Revised National Tuberculosis Control Program (RNTCP) Directly Observed Treatment, Short-Course regimen. ${ }^{[4]}$ They observed that $75 \%$ of patients were treated successfully, with a mortality rate of $3.3 \%$ and a treatment default rate of $6.6 \%$. Even though this meets the RNTCP success rate, it is not satisfactory for a disease with effective treatment and more than 20 drugs. This study also highlights the issues faced during treatment including paradoxical response, complications such as hydrocephalus and vasculitis, visual loss due to optochiasmatic arachnoiditis, and antituberculous therapy (ATT)-induced hepatitis.

Hydrocephalus is the most common complication of TBM. This occurs due to the basal exudates and inflammation leading to fibrosis and aqueductal obstruction and is usually obstructive type but may also be communicating type. The usual treatment for hydrocephalus, ventriculoperitoneal (VP) shunting should not be the first line in TBM hydrocephalus. Shunt obstruction and secondary infection are common in the setting of TBM and lead to high mortality and morbidity. In a study of 65 patients treated with VP shunt for TBM, the complication rate was as high as $32.3 \%{ }^{[5]}$ Hence, VP shunt in hydrocephalus due to TBM should be reserved for cases resistant to medical therapy.

Paradoxical response is another challenge in treating CNS-TB, which merits some discussion. This refers to clinical deterioration with the appearance of new lesions and/or enlargement of existing lesions on ATT. Usually, this occurs in patients with TBM on ATT when they develop tuberculomas. In one study, paradoxical response occurred in about $15 \%$ of treated TBM cases after a mean duration of 6 months (range 1-17 months). ${ }^{[6]}$ This can be due to immune reconstitution or antimycobacterial drug resistance in TB bacilli. During active disease, the activation of monocytes by mycobacterial antigens such as D-Arabino-D-galaction leads to the secretion and immunosuppressive concentrations of anti-inflammatory prostaglandin $\mathrm{E}_{2}$. Once the active disease is treated, immune reconstitution occurs with the return of delayed type hypersensitivity to TB bacilli and antigens, leading to the activation of macrophages and lymphocytes and forming granuloma and tuberculomas. Hence, intensifying ATT during paradoxical response may not be logical. However, this needs further confirmation in large prospective trials. Another differential that should be considered while dealing with a paradoxical response is whether the original diagnosis of tuberculoma is correct. Many times, it might be a glioma, lymphoma or other granuloma that are progressing due to incorrect diagnosis and treatment.

To conclude, among the spectrum of TB, CNS-TB is probably the most devastating and challenging to treat. 
As more clinical studies are published, it leaves more questions than answers. There are a lot of unmet needs in the management of CNS-TB including standard protocols, better and affordable drugs with good CNS penetration and safety, wide availability of GeneXpert MTB/RIF, especially to economically backward regions, and awareness among doctors regarding TBM and early (often empirical) ATT.

Joe James

Department of Neurology, Government Medical College, Kozhikode, Kerala, India

\section{Address for correspondence: Dr. Joe James, Njaralakatt House, Pottangadi Road, West Nadakkav, Kozhikode - 673 011, Kerala, India. E-mail: drjoejames@gmail.com}

\section{REFERENCES}

1. Global tuberculosis report 2017. Geneva: World Health Organization; 2017. Licence: CC BY-NC- SA 3.0 IGO.

2. Be NA, Kim KS, Bishai WR, Jain SK. Pathogenesis of central nervous system tuberculosis. Curr Mol Med 2009;9:94-9.

3. Green JA, Dholakia S, Janczar K, Ong CW, Moores R, Fry J, et al. Mycobacterium tuberculosis-infected human monocytes down-regulate microglial MMP-2 secretion in CNS tuberculosis via TNF $\alpha, \mathrm{NF \kappa B}, \mathrm{p} 38$ and caspase 8 dependent pathways.
J Neuroinflammation 2011;8:46.

4. Maheswari EU, Bhoopathy RM, Bhanu K, Anandan H. Clinical spectrum of central nervous system tuberculosis and the efficacy of revised national tuberculosis control program in its management. J Neurosci Rural Pract 2018;10:71-7.

5. Lamprecht D, Schoeman J, Donald $P$, Hartzenberg $H$. Ventriculoperitoneal shunting in childhood tuberculous meningitis. Br J Neurosurg 2001;15:119-25.

6. Gupta M, Bajaj BK, Khwaja G. Paradoxical response in patients with CNS tuberculosis. J Assoc Physicians India 2003;51:257-60.

This is an open access journal, and articles are distributed under the terms of the Creative Commons Attribution-NonCommercial-ShareAlike 4.0 License, which allows others to remix, tweak, and build upon the work non-commercially, as long as appropriate credit is given and the new creations are licensed under the identical terms.

\begin{tabular}{|l|l|}
\hline \multicolumn{2}{|c|}{ Access this article online } \\
\hline Quick Response Code: & Website: \\
\hline
\end{tabular}

How to cite this article: James J. Central nervous system tuberculosis - The gray area in tuberculosis treatment. J Neurosci Rural Pract 2019;10:6-7. 